\title{
BMJ Open Qualitative analysis of 6961 free-text comments from the first National Cancer Patient Experience Survey in Scotland
}

\author{
Maggie Cunningham, Mary Wells
}

To cite: Cunningham $\mathrm{M}$, Wells M. Qualitative analysis of 6961 free-text comments from the first National Cancer Patient Experience Survey in Scotland. BMJ Open 2017;7:e015726. doi:10.1136/ bmjopen-2016-015726

- Prepublication history for this paper is available online. To view these files please visit the journal online (http://dx.doi. org/10.1136/bmjopen-2016015726).

Received 23 December 2016 Revised 27 February 2017 Accepted 20 March 2017
CrossMark

NMAHP Research Unit, University of Stirling, Stirling, UK

Correspondence to Professor Mary Wells; mary.wells@stir.ac.uk

\begin{abstract}
Objectives To analyse free-text responses from the first Scottish Cancer Patient Experience Survey (SCPES) to understand patients' experiences of care, identify valued aspects and areas for improvement.

Design Inductive thematic analysis of seven freetext comment boxes covering all stages of the cancer experience, from a national cohort survey.

Setting and participants Adult cancer patients diagnosed across all Health Boards in Scotland between July 2013 and March 2014, and who had an inpatient stay or hospital visit between January and September 2014. 2663 respondents (of $n=4835$ survey respondents) provided 6961 free-text comments.
\end{abstract}

Main outcome measures Positive and negative themes of patients' experiences. Differences in the proportion of positive to negative comments by demographics. Methods Data were analysed as follows: (1) comments were initially categorised at a high level (eg, positive, negative, miscellaneous, etc); (2) inductive codes were derived and applied to all relevant comments; (3) codes sharing similar meaning were amalgamated into subthemes, and code frequencies were measured; (4) subthemes were mapped into overarching themes; (5) difference in the proportion of positive to negative comments by demographics were analysed using $\chi^{2}$ tests. Results Participants made more positive than negative comments (1:0.78). Analysis highlighted the importance to patients of Feeling that Individual Needs Are Met and Feeling Confident Within the System. Comments also provided insight into how Processes and Structures within the system of care can negatively impact on patients' experience. Particular issues were identified with care experiences in the lead-up to diagnosis.

Conclusions This analysis provides a detailed understanding of patients' cancer care experiences, therefore indicating what aspects matter in those experiences. Although the majority of comments were positive, there were a significant number of negative comments, especially about the lead-up to diagnosis. Comments suggest patients would value greater integration of care from services involved in their treatment for cancer.

\section{INTRODUCTION}

Finding ways to deliver high-quality, person-centred care is central to National Health Service (NHS) policy, and has been
Strengths and limitations of this study

- Large data set from a national survey.

- Use of seven free-text comment boxes gives patients a chance to comment on all aspects of the cancer patient experience.

- Analysis by each comment box gave clear indication of stages of care which are of specific concern.

- Analysis across the whole data set identified themes about their cancer care which are of particular importance to patients.

- Free-text responses to surveys may not be representative of all patients' experiences.

driven by rising demands, financial pressures, concerns about standards of care and a greater focus on the 'consumer's' perspective. ${ }^{1}$ Patient experience is recognised as one of the critical elements of high-quality healthcare, along with clinical effectiveness and safety. ${ }^{2}$ Not just important in itself, patient experience has been shown to be positively associated with a range of health, resource use and safety outcomes. ${ }^{3}$ In NHS England, a measure of patient experience is included as one of four key metrics contributing to each Clinical Commissioning Group's overall rating for cancer care. ${ }^{4}$ Assessing the patient's perspective provides valuable insights into how the whole healthcare system impacts on the patient's experience across the care continuum, rather than looking at individual services in isolation from a clinical or hospital management standpoint. ${ }^{5}$

Cancer remains a leading cause of death worldwide and will affect one in two people in the UK during their lifetime. ${ }^{6}$ For many patients, being diagnosed and treated for cancer is a long and complicated process, involving multiple stages of investigation and treatment, and multiple encounters with a variety of health professionals and services. Several surveys have been conducted by researchers to gain a better understanding of experience of care for patients with cancer, 
although the majority of these look at particular aspects of the care trajectory, for example, follow-up care, ${ }^{7}$ hospital care, ${ }^{8}$ or at specific types of cancer, for example, breast, ${ }^{9}$ lung and colorectal. ${ }^{10}$

National Cancer Patient Experience Surveys have been carried out every 18-20 months in England since 2010, ${ }^{11}$ and also in Norway, ${ }^{12}$ Northern Ireland ${ }^{13}$ and Wales. ${ }^{14}$ This is the first time such a survey has been conducted in Scotland. The quantitative results of the Scottish Cancer Patient Experience Survey (SCPES) were published in June 2016, highlighting that the majority of patients have a positive experience of care overall, and that many aspects of care provision are working well. ${ }^{15}$ However, the results also draw attention to particular areas of care which are less positive and require service improvement. ${ }^{15}$

Previous research has found that clinical staff find quantitative data of limited use in designing service improvements as they do not provide a sufficiently detailed description of the issues which matter to patients. ${ }^{16}$ Including free-text comments in experience surveys has the potential to overcome this problem, giving the patient a voice to influence service improvement. ${ }^{17}$ Data from free-text comments can give patients the opportunity to explain their experiences in more detail, providing deeper insights into patients' experiences, in particular providing an opportunity for patients to be critical of specific aspects of their care. ${ }^{17}$ Previous UK national surveys have included three brief opportunities for free-text comments, asking 'was there anything particularly good about your NHS cancer care?', 'was there anything that could have been improved?' and 'any other comments?' at the end of the survey. ${ }^{18}$ The SCPES steering group made a decision to include a free-text question at the end of each section of the survey, providing an opportunity for patients to write about different aspects of their cancer care in more detail.

The present paper reports on the thematic analysis of all free-text comments provided by participants in the 2015-2016 SCPES. The purpose of the analysis was to understand the full breadth of experiences of care for patients with cancer in their own words, and from this to identify the aspects of the cancer care experience which participants particularly valued, and also to explore themes which highlight areas for improvement in cancer services.

\section{METHODS}

\section{Study design}

Data gathering for SCPES took place between 7 October 2015 and 22 January 2016. Jointly funded by the Scottish Government and Macmillan Cancer Support, the survey was posted to all NHS Scotland patients who met the following inclusion criteria:

- Diagnosed with any cancer between July 2013 and March 2014.

- Had an inpatient stay or hospital visit as a day case between 1 January and 30 September 2014.

In total, 7949 survey packs were sent. Two reminder letters were sent to non-responders after 3 weeks and 6 weeks. Patients could respond to the survey via freepost return, or by completing the survey online.

\section{Survey}

The survey questionnaire was based on the equivalent English National Cancer Patient Experience Survey, ${ }^{18}$ with 69 questions covering referral to hospital by the general practitioner (GP), diagnosis, decisions about treatment, role of the clinical nurse specialist, support for people with cancer, hospital doctors and ward nurses, hospital care and treatment, radiotherapy and chemotherapy, home care and support, care from general practice and overall NHS care. In addition, seven free-text comment boxes were included throughout the questionnaire asking participants if there was anything else they would like to add about their experiences in relation to seven areas of care (table 1). Demographic and clinical information were collected including gender, age, socioeconomic

Table 1 Comment boxes

Question topic: is there anything else you would like to tell us about...

Preceding questionnaire section headings

\begin{tabular}{lll}
\hline Comment box 1 & $\begin{array}{l}\text { The lead-up to your cancer diagnosis, or the } \\
\text { way you found out you had cancer }\end{array}$ & $\begin{array}{l}\text { Seeing your GP, diagnostic tests, finding out what } \\
\text { was wrong with you }\end{array}$ \\
Comment box 2 & $\begin{array}{l}\text { The way decisions were made about your } \\
\text { treatment }\end{array}$ & $\begin{array}{l}\text { Deciding the best treatment for you } \\
\text { Comment box } 3\end{array}$ \\
$\begin{array}{lll}\text { The support you received (including from a } \\
\text { clinical nurse specialist) }\end{array}$ & $\begin{array}{l}\text { Clinical nurse specialist, } \\
\text { support for people with cancer }\end{array}$ \\
Comment box 4 & $\begin{array}{l}\text { The care you received when you had an } \\
\text { operation or stayed overnight in hospital }\end{array}$ & Operations, hospital care as an inpatient \\
Comment box 5 & The day patient/outpatient care you received & Hospital care as a day patient/outpatient \\
Comment box 6 & Your chemotherapy/radiotherapy treatment & Radiotherapy and chemotherapy \\
Comment box 7 & Your experiences of cancer care & Home care and support, care from your general \\
\hline
\end{tabular}


status (using the Scottish Index of Multiple Deprivation (SIMD)), ethnicity, sexual orientation, employment status and tumour group. Anonymised data were transferred from the Scottish Government to the researchers, using encrypted software.

\section{Governance}

The approvals process for the survey was led by the Information Services Division (ISD). Approval for analysis of the fully anonymised comments by the research team was given by the Public Benefits and Privacy Panel (http:// www.informationgovernance.scot.nhs.uk/pbpphsc).

\section{Analysis}

\section{Qualitative analysis}

Free-text comments were analysed using thematic analysis, ${ }^{19}$ employing an inductive approach-coding and theme development were driven by the content of the comments. Analysis of the large data set was carried out using a structured approach..$^{20}$ The data were divided into responses for each of the comment boxes, creating seven data sets. These data sets were initially analysed separately, before being considered as a whole during the creation of themes. One researcher (MC) familiarised herself with the data for each comment box by reading all of the responses. Notes were made of any potential codes for each individual data set by identifying recurring words or units of meaning. A second researcher (MW) familiarised herself with a random sample of the responses and the two researchers discussed and agreed coding decisions. In order to further structure the data, responses were sorted into first order codes based on whether the comment was (1) positive; (2) negative; (3) entirely factual/neutral, for example, 'no treatment required after operation'; (4) entirely irrelevant/miscellaneous, for example, 'operation at (hospital name removed)'; (5) contained both positive and negative comments. If a comment contained, for example, both positive and neutral content, it would be coded as a positive comment. Comments which were entirely factual/neutral or irrelevant/miscellaneous were not included in further analysis. MC then applied second order codes to all remaining comments in each individual data set. Because the second order codes had been derived inductively from the data, the coding sheet was different for each of the seven data sets. In total, there were 174 second order codes across the seven comment boxes. Comments were given as many codes as were appropriate to cover the content of the comment, for example, the comment 'Food and ward hygiene were disgusting' was given the first order code 'negative' and the second order codes 'bad food' and 'hygiene issues'. Comments were then grouped by second order code and reread and compared in order to check for consistency of meaning within the code. During this process of constant comparison, codes were amalgamated, or new codes were created as differences in meaning were identified. A third researcher (PA) checked first and second order coding decisions for a random $5 \%$ of the comments. Any discrepancies or disagreements (of which there were only a small number) were discussed by the team, and adjustments made if necessary. Two researchers (MC and MW) worked together to compare, contrast and consolidate codes by identifying similar codes and discussing differences across the seven comment boxes. Many codes that were identified in particular comment boxes also emerged in other comment boxes, indicating that there were recurring issues that were relevant to all aspects of the cancer experience. Therefore, codes which shared similar meaning were amalgamated into subthemes. For example, the codes 'hygiene issues', 'uncomfortable environment', 'unhygienic, noisy, bad food', 'uncomfortable environment', 'bad food', 'too noisy', 'poor facilities', 'bad food, food not as recommended', 'poor facilities/ uncomfortable' and 'problems with ward environment', which emerged across the comment boxes, were amalgamated into the subtheme "unsuitable or uncomfortable environment'. The subthemes were therefore relevant to all aspects of the patients' experience of care. Code frequencies were measured to give an indication of the prominence of different subthemes. Subthemes were then mapped by MW and MC into overarching themes which encompassed and described the main issues highlighted in the data. Several subthemes were related to patients' perceptions of the way care was organised, and the other subthemes were related to how patients actually experienced their care.

Subthemes are illustrated with quotes in tables 2 and 3. In order to preserve context, comments have been presented in full. This may mean in some cases that quotes represent more subthemes than the one they are presented next to in the table. An individual respondent could contribute to more than one subtheme if their free-text comment covered several issues. The number of comments reported in the tables are the number of comments which included information for each subtheme.

\section{Quantitative analysis}

First order positive and negative coding for each of the comments were analysed by key demographics-gender, age, socioeconomic status, employment status, tumour group and health board-using $\chi^{2}$ tests. The proportion of participants who made a positive comment was compared with the proportion who made a negative comment across each demographic category, for each of the comment boxes. Standardised adjusted residuals were calculated for each of the cells of data in order to identify which differences between observed and expected cell counts contributed to statistically significant $\chi^{2}$ results. Standardised adjusted residuals of $\geq 1.96$ indicate there is a statistically significant difference between the number of cases observed in that cell, and the number expected if the null hypothesis is true, that is, that the demographic has no bearing on the proportion of positive and negative comments. 
Table 2 Summary of the positive themes

\begin{tabular}{|c|c|c|}
\hline Themes & $\begin{array}{l}\text { Number of } \\
\text { comments }\end{array}$ & $\begin{array}{l}\text { Quotes } \\
\text { (Gender, age bracket, type of cancer) }\end{array}$ \\
\hline Generally positive experience & 1995 & $\begin{array}{l}\text { All in all very good. } \\
\text { Female, } 66-75, \text { breast cancer }\end{array}$ \\
\hline Good support & 738 & $\begin{array}{l}\text { Clinical nurse was extremely helpful and gave me great friendship and support } \\
\text { during this horrendous time. A great font of knowledge with financial help, the } \\
\text { benefits I could apply for. She assisted in the filling out of complicated forms. A } \\
\text { real treasure. } \\
\text { Female, } 66-75 \text {, haematological cancer }\end{array}$ \\
\hline Information & 508 & $\begin{array}{l}\text { I had/have an excellent consultant surgeon by the name of Mr (name removed). } \\
\text { I have had the best of care and attention from him. Despite being an extremely } \\
\text { busy man, he always has time to spend with me and my wife at appointments. } \\
\text { He explains everything very clearly and answers our questions thoroughly. In } \\
\text { my opinion I couldn't ask for a better man to care for me. } \\
\text { Male, } 66-75 \text {, colorectal/lower gastrointestinal cancer }\end{array}$ \\
\hline Good clinical care & 362 & $\begin{array}{l}\text { Despite complications and infections arising from my prostate removal the care } \\
\text { and attention that I received from (name removed) and his team of doctors and } \\
\text { nurses was of the highest order. I could have no complaints. Very impressive } \\
\text { urology care team. } \\
\text { Male, 66-75, prostate cancer }\end{array}$ \\
\hline Efficient processes & 279 & $\begin{array}{l}\text { I was admitted to the (hospital name removed) after presenting to my GP with } \\
\text { (condition removed). Had ultrasound, MRI and CT scan all within } 5 \text { days and } \\
\text { due to tumour was transferred to the (hospital name removed), scoped and } \\
\text { biopsy taken and I had my full diagnosis within } 3 \text { weeks and chemotherapy } \\
\text { started within } 5 \text { weeks. } \\
\text { Male, } 51-65 \text {, upper gastrointestinal cancer }\end{array}$ \\
\hline Trust in the system & 81 & $\begin{array}{l}\text { Discussions were business-like. Facts were presented to me, questions } \\
\text { answered and information was very clear and decisions agreed. It was a very } \\
\text { democratic, and respectfully conducted process. } \\
\text { Male, 66-75, upper gastrointestinal cancer }\end{array}$ \\
\hline
\end{tabular}

Participants who made comments which were both positive and negative, or who made factual/neutral or irrelevant/miscellaneous comments were excluded from this analysis. The $\chi^{2}$ tests were not performed for ethnicity and sexual orientation due to the low number of respondents for these demographics.

Due to the low number of respondents in certain categories, brain, central nervous system and sarcoma cancer types were merged, as were the age bands $16-25$ years and 26-35 years. Comments from three rural health boards (NHS Orkney, NHS Shetland and NHS Western Isles) were omitted due to having less than five respondents who made at least one free-text comment.

\section{FINDINGS}

Four thousand eight hundred and thirty-five patients completed the survey, a $61 \%$ response rate. Of those patients, $2663(55 \%)$ left at least one free-text comment. There were differences in clinical or sociodemographic characteristics between those respondents who left at least one comment, and those respondents to the survey who left no comment (table 4). Women, respondents aged 35-44 years and 45-54 years and part-time workers were more likely to leave a comment and respondents aged
76 years and over, those who were retired, those from the most deprived areas, and respondents with prostate cancer or cancer from an unknown tumour group were less likely to leave a comment. In total 6961 comments were made by respondents. Overall, more positive $(2,528)$ than negative $(1,969)$ comments were made, a ratio of 1:0.78 (table 5). Positive comments (average 24 words) tended to be shorter, more generic and less detailed than negative comments (average 43 words). Respondents made more positive than negative comments for all comment boxes except comment box 1 (the lead-up to diagnosis), where a significantly greater number of negative comments were made (571 negative, 369 positive, $\left.\chi^{2}(6)=200.6, p<0.001\right)$.

\section{Qualitative findings}

\section{Positive comments}

Themes emerging from the positive comments are illustrated with quotes in table 2 . The majority of these comments reflected a generally positive experience, with respondents describing their care as good, very good or excellent. Many of these positive comments lacked any detail as to which aspects of the experience were particularly valued by patients. 


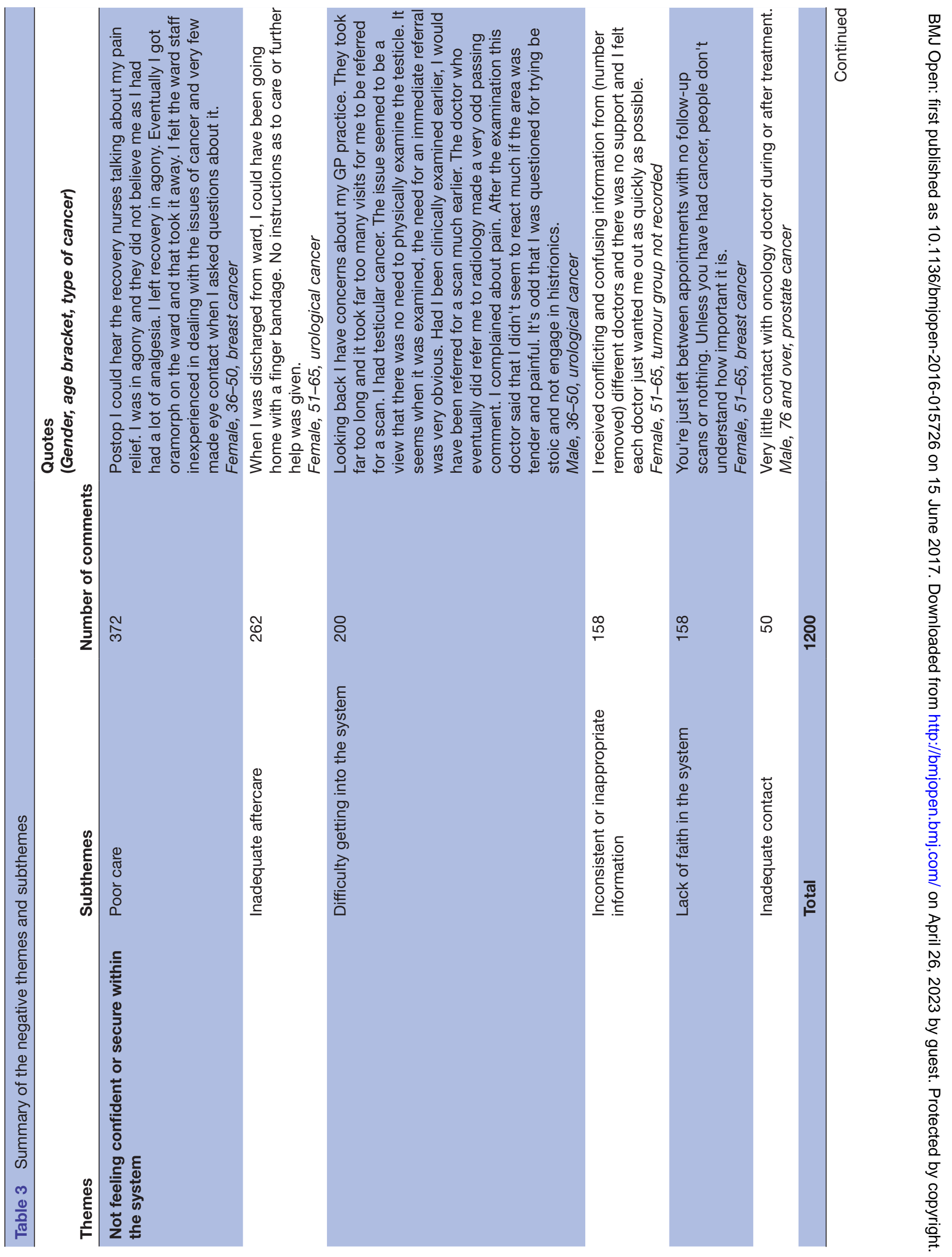




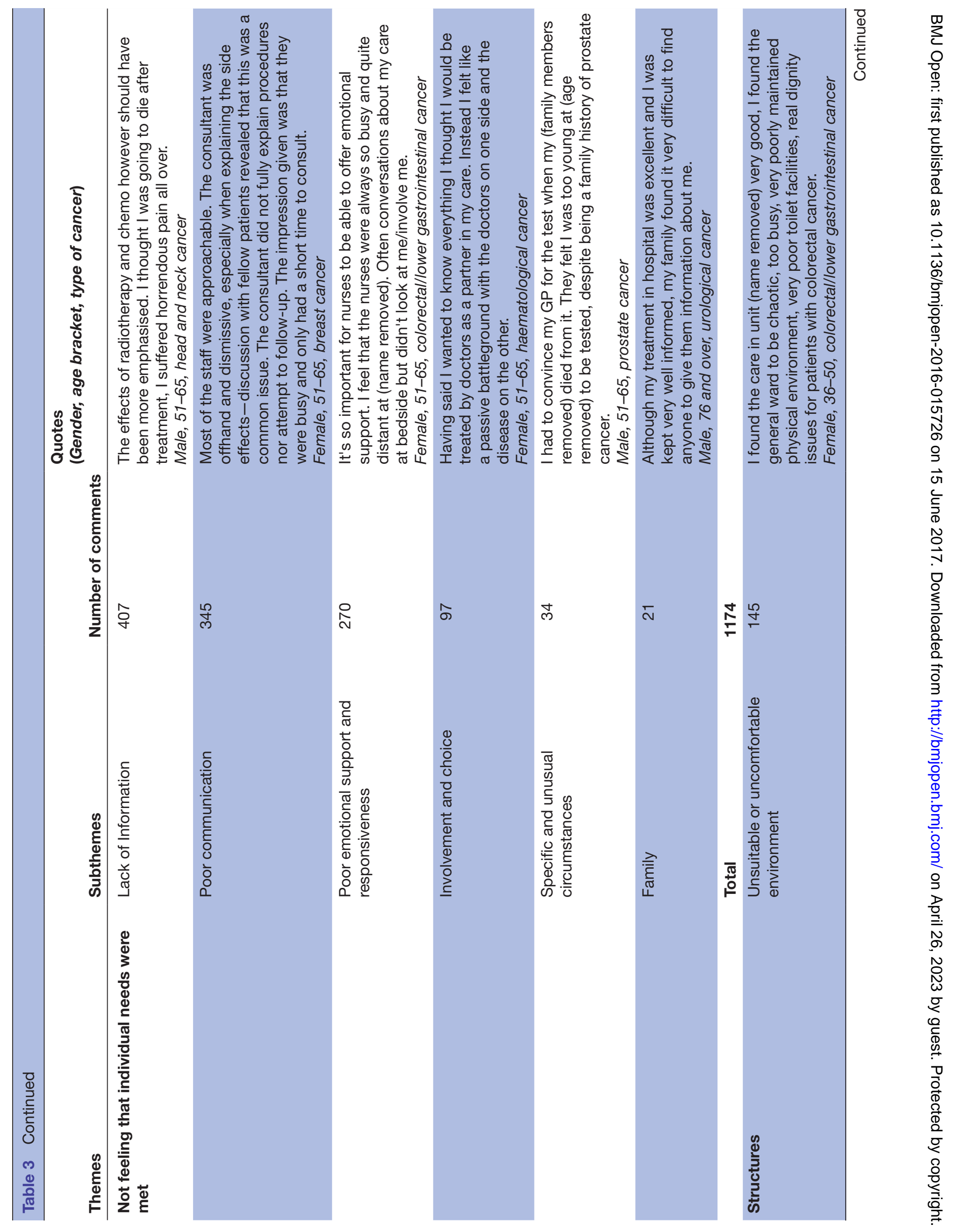




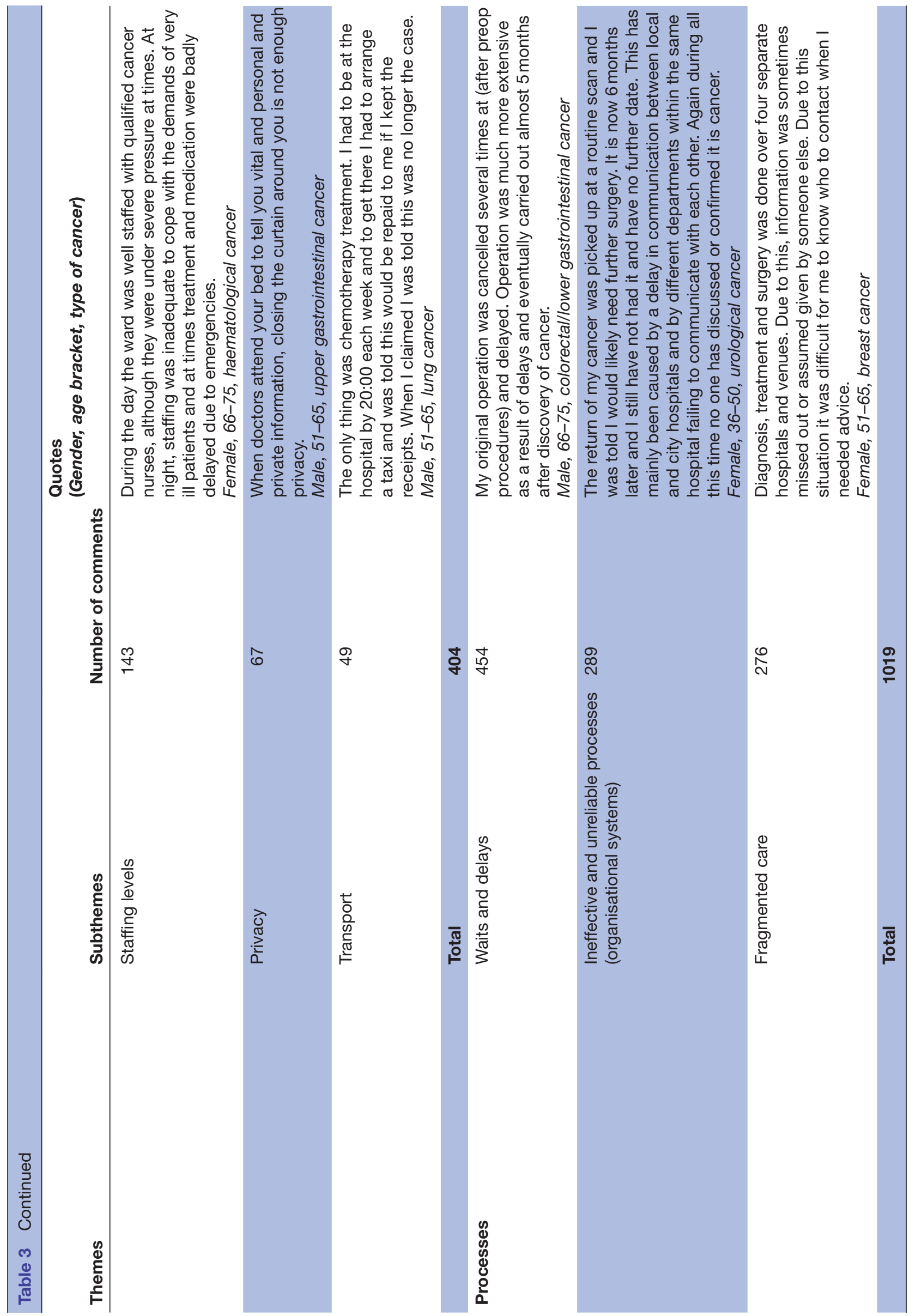

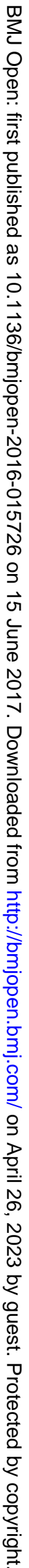


Open Access

Table 4 Demographic details of all respondents and those that left at least one comment

\begin{tabular}{|c|c|c|c|c|}
\hline \multirow[b]{2}{*}{ Respondent characteristics } & \multicolumn{2}{|c|}{ Left at least one comment } & \multicolumn{2}{|c|}{ Respondents who left no commen } \\
\hline & $\begin{array}{l}\text { Number of } \\
\text { respondents }\end{array}$ & Percentage & $\begin{array}{l}\text { Number of } \\
\text { respondents }\end{array}$ & Percentage \\
\hline \multicolumn{5}{|l|}{ Age, years } \\
\hline $16-34$ & 47 & 2 & 38 & 2 \\
\hline $35-44$ & 130 & 5 & 52 & 3 \\
\hline $45-54$ & 369 & 14 & 241 & 12 \\
\hline $55-64$ & 649 & 25 & 487 & 24 \\
\hline $65-74$ & 864 & 34 & 766 & 37 \\
\hline \multirow[t]{2}{*}{ Age $75+$} & 512 & 20 & 486 & 23 \\
\hline & \multicolumn{4}{|c|}{$\chi^{2}(5)=37.3, p \leq 0.001$} \\
\hline \multicolumn{5}{|l|}{ Gender } \\
\hline Female & 1520 & 59 & 1139 & 54 \\
\hline \multirow[t]{2}{*}{ Male } & 1072 & 41 & 973 & 46 \\
\hline & \multicolumn{4}{|c|}{$\chi^{2}(1)=10.5, p=0.001$} \\
\hline \multicolumn{5}{|l|}{ Sexual orientation } \\
\hline Heterosexual & 2517 & 99 & 2028 & 99 \\
\hline \multirow[t]{2}{*}{ Bisexual, gay or lesbian, or other } & 27 & 1 & 20 & 1 \\
\hline & \multicolumn{4}{|c|}{ No significant difference } \\
\hline \multicolumn{5}{|l|}{ Ethnic origin } \\
\hline White & 2558 & 99 & 2077 & 98 \\
\hline \multirow[t]{2}{*}{ All other ethnic origins } & 29 & 1 & 33 & 2 \\
\hline & \multicolumn{4}{|c|}{ No significant difference } \\
\hline
\end{tabular}

\section{Employment status}

$\begin{array}{lllll}\text { Don't work due to illness or disability } & 227 & 9 & 156 & 7 \\ \text { Other } & 42 & 2 & 47 & 2 \\ \text { Retired } & 1568 & 60 & 1363 & 64 \\ \text { Unemployed/looking for work } & 21 & 1 & 22 & 1 \\ \text { Work full time/in full time education } & 458 & 18 & 347 & 14 \\ \text { Work part-time } & 289 & 11 & 192 & 9\end{array}$

\section{SIMD quintile (2012)}

\begin{tabular}{|lllll|}
\hline (most deprived) 1 & 327 & 13 & 381 & 19 \\
\hline 2 & 453 & 18 & 351 & 18 \\
\hline 3 & 530 & 21 & 381 & 19 \\
\hline 4 & 572 & 23 & 432 & 22 \\
\hline (least deprived) 5 & 644 & 25 & 435 & 22 \\
\hline Tumour group & $\chi^{2}(4)=35.8, \mathrm{p} \leq 0.001$ & & \\
\hline Brain/central nervous system & 21 & & & 1 \\
\hline Breast & 659 & 1 & 528 & 24 \\
\hline Colorectal/lower gastrointestinal & 427 & 25 & 294 & 14 \\
\hline Gynaecological & 213 & 16 & 146 & 7 \\
\hline Haematological & 215 & 8 & 164 & 8 \\
\hline Head and neck & 148 & 6 & 116 & 5 \\
\hline Lung & 163 & 6 & 129 & 6 \\
\hline
\end{tabular}


Table 4 Continued

\begin{tabular}{lllll}
\hline & \multicolumn{2}{l}{ Left at least one comment } & \multicolumn{2}{l}{ Respondents who left no comment } \\
\cline { 2 - 5 } Respondent characteristics & $\begin{array}{l}\text { Number of } \\
\text { respondents }\end{array}$ & Percentage & $\begin{array}{l}\text { Number of } \\
\text { respondents }\end{array}$ & Percentage \\
\hline Prostate & 290 & 11 & 302 & 14 \\
\hline Sarcoma & 20 & 1 & 14 & 1 \\
Skin & 70 & 3 & 59 & 3 \\
Upper gastrointestinal & 118 & 4 & 71 & 6 \\
Urological & 173 & 6 & 135 & 9 \\
Other/tumour group unknown & 146 & 5 & 196 &
\end{tabular}

Where respondents did give more detail about the aspects of care which gave them a positive experience, the most common theme was good support. Within this theme, respondents described being cared for both practically and emotionally, and being treated as an individual. Comments about good support related to care received from NHS staff, in particular from clinical nurse specialists and GPs, and also to support received through a range of charities. However, many participants commented that they had found out about the support available from charities through word of mouth, for example, from other patients rather than having been signposted by NHS staff.

Another common positive theme was information, with participants describing how much they valued receiving clear information and thorough explanations of their cancer and treatment, including treatment options. The manner in which information was conveyed was also important, with participants appreciating sensitive communication from staff who gave them the time to process information and ask questions.

Further positive comments related to receiving good clinical care. Respondents commented on treatment going well, good symptom management and having faith in the clinical competence of staff. Participants expressed their confidence when they felt that they were being treated by a cohesive team, appreciating communication and continuity of care. Many participants were relieved and grateful that their GP had identified symptoms and organised diagnostic testing for cancer.

Respondents commented positively on efficient processes, mainly in relation to the speed of treatment, both in referral for tests before diagnosis, and in the efficient running of outpatient clinics. The smooth running and speed of various national screening programmes was also commented on favourably.

The final distinct positive theme suggested by the data was trust in the system, with respondents particularly valuing knowledgeable staff, and a collaborative and inclusive approach to decision making about treatment.

\section{Negative comments}

Four broad themes emerged from analysis of the negative comments in the survey as depicted in figure 1. A number of subthemes were identified within these four overarching themes, and these are illustrated by selected quotes in table 3 . The subthemes clearly suggested that negative experiences were related to (1) Patients not feeling confident or secure within the system, or (2) Patients not feeling that their individual needs were met. Other subthemes related to participants' perceptions of the way care was organised and these were grouped into (3) the way services and environments are set up (which we termed structures), and (4) the organisation of care and treatment (which we termed processes).

Table 5 First order code by comment box

\begin{tabular}{lllllcr}
\hline Comment box & Positive & Negative & Factual/neutral & $\begin{array}{l}\text { Irrelevant/ } \\
\text { miscellaneous }\end{array}$ & $\begin{array}{l}\text { Both positive } \\
\text { and negative }\end{array}$ & Total \\
\hline 1 & 369 & 571 & 597 & 22 & 114 & 1673 \\
\hline 2 & 338 & 260 & 242 & 12 & 39 & 891 \\
\hline 3 & 499 & 232 & 76 & 8 & 83 & 898 \\
\hline 4 & 478 & 293 & 88 & 144 & 117 & 1120 \\
\hline 5 & 292 & 153 & 46 & 143 & 44 & 678 \\
6 & 197 & 105 & 65 & 211 & 48 & 626 \\
\hline 7 & 355 & 355 & 1208 & 585 & 226 & 1075 \\
\hline Total & 2528 & 1969 & & 671 & 6961 \\
\hline
\end{tabular}




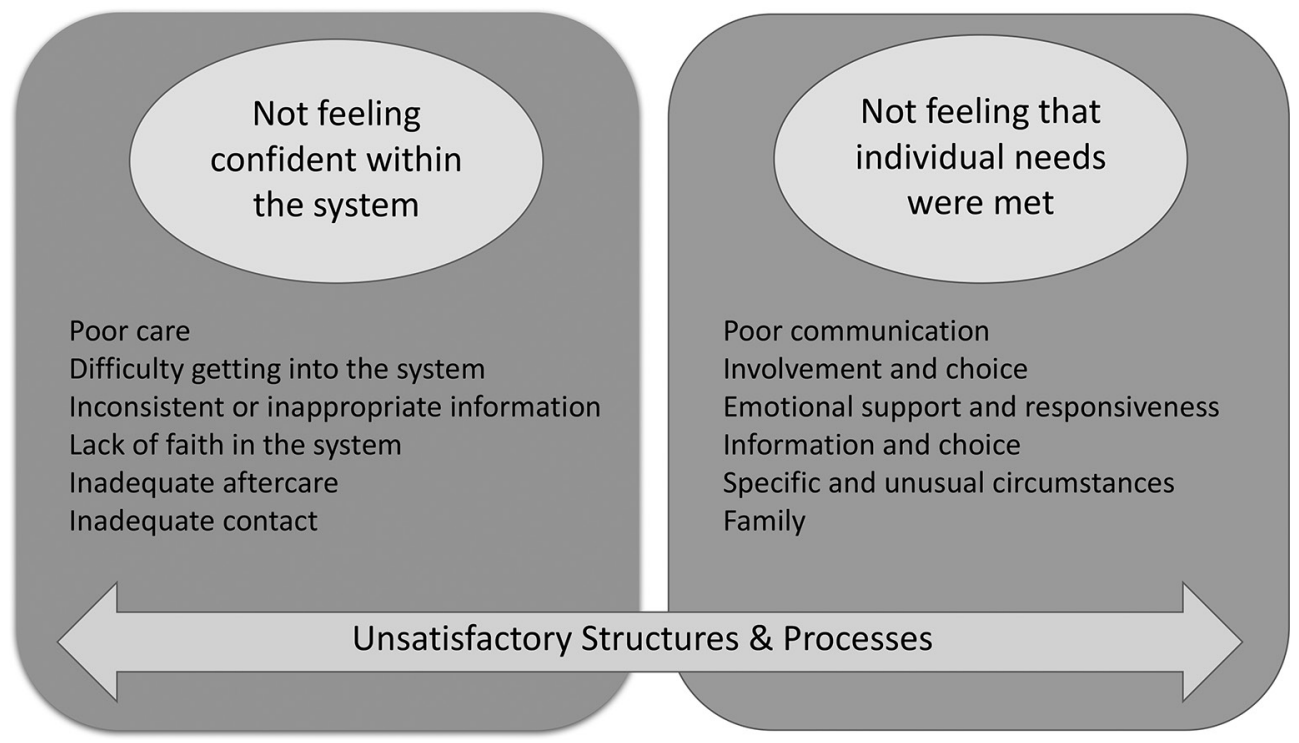

Figure 1 Negative aspects of care.

Although there were not as many negative comments as there were positive, the negative comments were much more specific and detailed, and gave a very clear picture of where improvement strategies could focus in order to enhance patients' experiences of cancer care.

The theme with the most negative comments, 'Not feeling confident or secure within the system', represented a number of subthemes (table 3). The most common subtheme was generated from comments about receiving poor care, particularly inadequate symptom management. Comments suggested that care was perceived to be poorer at night and at weekends, as well as on general rather than specialist wards. Many respondents described deficiencies in care and support after treatment had ended, including not receiving sufficient contact or emotional support and feeling isolated and alone, not being sure who to contact when they had cancer or treatment related problems, not receiving enough help with management of side effects and feeling that they received inadequate information about ongoing monitoring. A concern for some respondents was the lack of contact or support they received from their GP practice, community nurse or district nurse. Concerns about the role of primary care in the cancer experience were also reflected in comments about difficulties getting into the system. The majority of comments in this subtheme described the delays and multiple visits to GPs experienced by some participants before they were referred for diagnostic tests. However, other issues with the lead-up to diagnosis were not with primary care, but with participants' understanding of diagnostic testing, reflected in comments about lack of faith in the system. Some participants described their confusion that diagnostic tests or screening had not identified cancer. Many respondents also lost confidence in the system when they were given inconsistent or incorrect information by different health professionals involved in their care. Others described a feeling of being in limbo because of waits and delays between one stage of treatment and the next, and a lack of communication during these uncertain and difficult times.

The second core theme which emerged was 'Not feeling that individual needs were met'. Within this theme the greatest number of comments related to information not being sufficient or specific enough to meet patients' individual needs. Some patients were clearly overwhelmed by the amount of information they received, but most expressed a wish that they had been given more detailed and honest information about treatment options, side effects and self-management, as well as about other services they could access for specific support and information, for example, on financial issues. Many participants gave examples of poor communication during their experience of being treated for cancer, illustrating incidents where members of staff were perceived as insensitive, rude or dismissive. Other communication problems related to the way some patients had been told they had cancer, with many feeling that the conversation was vague, rushed or not handled sensitively. Lack of emotional support was also mentioned by many respondents, particularly if they did not have access or were not referred to a clinical nurse specialist or Macmillan service. Some felt they had not been listened to, or they experienced a lack of continuity in support (eg, when staff changed, went on holiday or were not available). Many participants expressed feelings of isolation and loneliness, both during and particularly after treatment, because they did not receive the support they needed.

The negative impact of structures and processes on experiences of cancer care was expressed through a considerable number of comments related to the way in which services were set up and organised. The most common issue under the theme of processes (the organisation of care and treatment) was waits and delays, covering waiting for appointments to be scheduled, waiting between 
one thing and the next thing happening, and waiting on the day of appointments. Many patients specifically mentioned waiting on the day of chemotherapy appointments, with some describing waits of several hours before their chemotherapy commenced. Other unsatisfactory processes related to experiences of ineffective and unreliable communication systems. Many participants described inefficient administrative procedures, including delays in letters being received by or sent to GPs, appointments not being arranged, and appointments being cancelled or postponed without adequate communication. One of the most common sources of concern was that monitoring and follow-up appointments were not always arranged in line with the expectations that had been set by clinicians, leaving considerable room for uncertainty and worry. Other experiences included notes going missing, problems with call handling, poor communication between departments and different sites not having access to full notes, all contributing to participants feeling passed around or feeling that their care was fragmented.

Participants also described a number of ways in which aspects of the care environment impacted negatively on their experiences. Particular issues highlighted under the theme of structures were related to lack of privacy, bed availability or aspects of comfort on wards (eg, meals, bathrooms), difficulties with transport and inadequate staffing levels.

\section{QUANTITATIVE ANALYSIS}

Differences in the proportion of positive to negative comments by demographics (gender, age, socioeconomic status, employment status, tumour group and health board) were analysed using $\chi^{2}$ tests for each of the seven comment boxes. The proportion of positive comments within each subcategory for age, employment status and tumour group is presented in table 6 .

There were significant differences in the experience of cancer care by age and employment status across the first five comment boxes (table 6). Younger participants were less likely to report a positive experience compared with participants over age 66 years, across all comment boxes except comment box 6 (chemotherapy/radiotherapy). A greater proportion of participants who worked full time, or who didn't work because they were either unemployed, a student or had an illness or disability, were negative about their experiences of cancer care across the first five comment boxes, whereas a greater than expected proportion of participants who were retired were positive about their experiences of cancer care.

There were significant differences in particular aspects of the experience of cancer care by tumour group (table 6). The proportion of positive to negative comments made in response to each comment box was compared for each of the cancer groups. There was a trend for participants with less common cancer types (eg, haematological, head and neck, gynaecological, brain, central nervous system (CNS), sarcoma and urological cancers) to make proportionately more negative comments about their experience of the lead-up to diagnosis (comment box 1). There was a trend for respondents with breast and urological cancers to report a proportionately greater number of negative experiences about their involvement in decision making, the support they received and inpatient care (comment boxes, 2, 3 and 4). Participants with lung cancer tended to make a greater proportion of positive comments about their experiences of support received, and inpatient and outpatient care. Finally, participants with upper gastrointestinal and head and neck cancers made a greater proportion of negative comments about their experience of day patient/outpatient care (comment box 5).

There were significant gender differences in the proportion of positive to negative comments for the way decisions were made about treatment (male, $\mathrm{n}=164$ $(66.9 \%)$ positive; female, $\mathrm{n}=169$ (49.3\%) positive; $\left.\chi^{2}(1)=18.2, p \leq 0.001\right)$, and participants' experience of the support they received (male, $\mathrm{n}=213(79.5 \%)$ positive; female, $\mathrm{n}=272(61.0 \%)$ positive; $\left.\chi^{2}(1)=26.3, \mathrm{p} \leq 0.001\right)$, with men being more likely than women to report a positive experience. This gender difference is significant in both participants with and without breast cancer, indicating it is not merely a breast cancer effect. There were no significant gender differences across any of the other comment boxes.

The only significant difference in the proportion of positive to negative comments by socioeconomic status was for inpatient care (comment box 4), where the least deprived participants made a greater proportion (46.6\%) of negative comments about their experience than participants from any of the other groups $(34.8 \%, 28.2 \%, 33.1 \%$, $38.9 \%$ for Scottish Index of Multiple Deprivation (SIMD) group $1-4$, respectively) $\left(\chi^{2}(4)=13.3, \mathrm{p}=0.10\right) .{ }^{21}$

There were no significant differences in the proportion of positive to negative comments across any of the demographics for comment box 6 (chemotherapy/ radiotherapy treatment) or comment box 7 (anything else about the experience of cancer care), except for an age effect in comment box 7 (with a greater proportion of negative comments in younger people, 16-35 years, $\mathrm{n}=6(31.6 \%)$ positive; $36-50$ years, $\mathrm{n}=36(40.9 \%)$ positive; $51-65$ years, $\mathrm{n}=126(45.3 \%)$ positive; $66-75$ years, $\mathrm{n}=116$ $(55 \%)$ positive; 76 years and over, $\mathrm{n}=63(63 \%)$ positive; $\left.\chi^{2}(4)=16.8, \mathrm{p}=0.002\right)$.

There were no significant differences in the proportion of positive to negative comments across any of the comment boxes by health board.

\section{DISCUSSION}

This is the first time that a nationwide survey has been conducted of experience of care of Scottish patients with cancer. Providing seven free-text comment boxes gave participants the opportunity to expand on particular aspects of their care which were important to them or had an impact on their overall experience. The analysis of the comments revealed that the ratio of positive to negative 
Table 6 Proportion of positive comments by comments box 1-5

\begin{tabular}{|c|c|c|c|c|c|}
\hline & $\begin{array}{l}\text { Lead-up to } \\
\text { diagnosis } \\
\text { (box 1) }\end{array}$ & $\begin{array}{l}\text { The way decisions } \\
\text { were made about } \\
\text { treatment (box 2) }\end{array}$ & $\begin{array}{l}\text { The support you } \\
\text { received (box 3) }\end{array}$ & $\begin{array}{l}\text { Inpatient care } \\
\text { (box 4) }\end{array}$ & $\begin{array}{l}\text { Day or outpatient } \\
\text { care (box 5) }\end{array}$ \\
\hline & $\begin{array}{l}\text { Positive } \\
\text { N (\%) }\end{array}$ & $\begin{array}{l}\text { Positive } \\
\text { N (\%) }\end{array}$ & $\begin{array}{l}\text { Positive } \\
\text { N (\%) }\end{array}$ & $\begin{array}{l}\text { Positive } \\
\text { N(\%) }\end{array}$ & $\begin{array}{l}\text { Positive } \\
\text { N (\%) }\end{array}$ \\
\hline \multicolumn{6}{|l|}{ Age, years } \\
\hline 16-35 & $6(22.2)$ & $4(26.7)$ & $9(60.0)$ & $8(47.1)$ & $2(25.0)$ \\
\hline $36-50$ & $41(29.5)$ & $40(50.0)$ & $60(60.0)$ & 50 (53.2) & 30 (46.9) \\
\hline $51-65$ & $118(32.6)$ & $115(48.1)$ & $178(62.5)$ & $165(55.6)$ & 109 (61.9) \\
\hline $66-75$ & $133(46.0)$ & $115(67.6)$ & $173(75.9)$ & $174(70.2)$ & 98 (76.6) \\
\hline \multirow[t]{2}{*}{76 and over } & $60(60.6)$ & $55(71.4)$ & 63 (75.9) & $73(74.5)$ & 49 (75.4) \\
\hline & $\chi^{2}(4)=40^{\star *}$ & $\chi^{2}(4)=29^{\star *}$ & $\chi^{2}(4)=16.3^{* *}$ & $\chi^{2}(4)=23.5^{\star \star}$ & $\chi^{2}(4)=26.3^{* *}$ \\
\hline \multicolumn{6}{|l|}{ Employment status } \\
\hline $\begin{array}{l}\text { Work full time/in full } \\
\text { time education }\end{array}$ & $51(26.3)$ & $62(53.4)$ & $76(58.5)$ & $74(51.7)$ & $44(50.0)$ \\
\hline Work part-time & $53(40.5)$ & $41(55.4)$ & $66(67.3)$ & $53(55.8)$ & $37(60.7)$ \\
\hline $\begin{array}{l}\text { Unemployed/ looking } \\
\text { for work }\end{array}$ & $4(44.4)$ & $1(12.5)$ & $1(14.3)$ & $1(25.0)$ & 1 (33.3) \\
\hline Retired & $224(46.8)$ & 198 (63.3) & $289(75.1)$ & $297(69.1)$ & $173(75.5)$ \\
\hline \multirow{2}{*}{$\begin{array}{l}\text { Don't work due to } \\
\text { illness or disability }\end{array}$} & $21(23.3)$ & $25(41.0)$ & $48(59.3)$ & $42(51.9)$ & $23(50.0)$ \\
\hline & $\chi^{2}(4)=34.8^{\star *}$ & $\chi^{2}(4)=18.5^{\star *}$ & $\chi^{2}(4)=26.6^{\star *}$ & $\chi^{2}(4)=22.9^{\star \star}$ & $\chi^{2}(4)=26.3^{\star \star}$ \\
\hline \multicolumn{6}{|l|}{ Tumour group } \\
\hline Lung & $24(46.2)$ & $20(64.5)$ & $31(83.8)$ & 40 (85.1) & 15 (88.2) \\
\hline Prostate & $41(48.8)$ & $42(55.3)$ & $61(83.6)$ & $37(58.7)$ & 30 (73.2) \\
\hline Upper gastrointestinal & $16(40.0)$ & $23(76.7)$ & $21(63.6)$ & $22(68.8)$ & $5(50.0)$ \\
\hline $\begin{array}{l}\text { Colorectal/lower } \\
\text { gastrointestinal }\end{array}$ & $70(46.1)$ & $61(69.3)$ & $90(75.0)$ & $91(62.8)$ & 35 (63.6) \\
\hline Breast & $100(41.7)$ & $74(46.8)$ & $112(55.7)$ & $111(55.0)$ & 65 (54.6) \\
\hline Haematological & $22(29.7)$ & $24(70.6)$ & $40(72.7)$ & $31(75.6)$ & $46(82.1)$ \\
\hline Head and neck & $17(29.8)$ & $25(56.8)$ & $36(83.7)$ & $31(66.0)$ & $12(52.2)$ \\
\hline Gynaecological & $28(31.8)$ & 24 (58.5) & $39(68.4)$ & 47 (61.0) & $34(79.1)$ \\
\hline $\begin{array}{l}\text { Brain/CNS/ } \\
\text { Sarcoma }\end{array}$ & 7 (33.3) & $8(66.7)$ & $11(68.8)$ & $8(50.0)$ & $6(66.7)$ \\
\hline Skin & $11(36.7)$ & $6(40.0)$ & $11(91.7)$ & $9(64.3)$ & $11(61.1)$ \\
\hline \multirow[t]{2}{*}{ Urological } & $16(27.6)$ & $19(47.5)$ & $25(58.1)$ & $34(60.7)$ & 18 (62.1) \\
\hline & $\chi^{2}(10)=18.5^{*}$ & $\chi^{2}(10)=24^{\star *}$ & $\chi^{2}(10)=40^{\star *}$ & $\chi^{2}(10)=20.5^{\star}$ & $\chi^{2}(10)=24.9^{\star \star}$ \\
\hline
\end{tabular}

${ }^{*} p<0.05,{ }^{* *} p<0.01$.

comments was 1:0.78, indicating that while the majority of patients had a positive experience of care, a significant minority had a negative experience, and this was particularly the case in the lead-up to diagnosis. Previous analysis of the closed-ended questions from the survey found that $94 \%$ of respondents rated their overall experience of care as good or very good. ${ }^{15}$ Analysis of the free-text comments provided a much greater insight into the specific problems participants had encountered during their cancer care. The generic nature of positive comments meant that there was less detailed analysis of the aspects of care which patients value. However, good support, clear information, good clinical care and efficient processes all emerged as positive themes for participants. Negative comments tended to be more detailed and specific and therefore provided richer material for analysis. Four themes emerged from the negative comments, highlighting the importance to people with cancer of feeling confident in the system and being treated as an individual. Analysis of the negative comments revealed that many participants had experienced problems with the way care was organised and services were set up. 
Although nothing emerged from the inductive thematic analysis about differences in experience of care as a result of sociodemographic characteristics, analysis of the positive and negative comments indicated that participants who were younger, who worked full time or who had certain types of cancer were more likely to report negative experiences. The demographic trends identified in this analysis were similar to the (English) National Cancer Patient Experience Survey 2011-2012 which found that female and younger patients are less likely to be positive about their cancer experience. ${ }^{22}$ Both the qualitative and quantitative results of the SCPES found that patients from the least deprived areas were more negative about their experience of inpatient care. ${ }^{15}$ Variations in the experience of care between demographic groups could represent differences in needs, expectations or the provision of care. ${ }^{22}$ While the analysis indicates that certain types of patients have a more negative experience of care, a cross-sectional survey cannot provide an explanation for differences by demographics, and further research is required to understand why certain patient characteristics are associated with reporting more negative experiences of care.

A strength of this study was the structured approach followed to analyse the large data set. ${ }^{20}$ However, the qualitative researcher is part of the analysis process, and makes subjective decisions about coding and the creation of subthemes and themes. While the analysis was conducted by a team of independent researchers and the process followed was transparent and rigorous, there will always be an element of subjectivity to qualitative analysis. The free-text comments formed part of a larger survey which also included closed-ended questions about patient experience. A limitation of this analysis is that data access issues meant we were not able to compare the quantitative and qualitative data. A further limitation was that no information was gathered about the health status of participants. Sending surveys to an entire cohort of patients maximised the opportunities to capture a wide range of experiences, and including seven free-text comment boxes placed throughout the survey gave participants the opportunity to reflect and comment on different stages of the cancer journey. The free-text questions focused on experiences of, rather than satisfaction with, care, removing the risks inherent in making assumptions about how patients evaluate satisfaction. ${ }^{23}$ However, there is a risk of bias in free-text responses towards patients who are more literate, have English as a first language, and who do not have learning difficulties. We found significant differences between participants who left a free-text comment and those who did not, with women, part-time and middle-aged respondents leaving a greater proportion of comments than expected, and respondents from the most deprived areas and those with prostate cancer leaving fewer comments than expected. Highlighting the importance of gathering patients' views on their healthcare may reduce intimidation and improve response rates from hard-to-reach patient groups. ${ }^{24}$
Although most of the issues within the subthemes were covered at some point in the closed-ended questions in the survey, participants often brought up issues, unprompted, in the qualitative comments before they had arisen in the questionnaire. For example, although the first three comment boxes and their preceding quantitative questions didn't ask specific questions about continuity of care, or being treated as an individual, both came out strongly in participants' comments. The content of the comment boxes also reflected specific issues covered in the preceding closed-ended questions. However, within the comments, participants gave much more depth and description about the issues.

SCPES was based on a survey which has been previously conducted in England and Wales, which asked participants what was particularly good, and what could have been improved about their cancer experience. ${ }^{18}$ Analysis of the free-text comments of London participants ${ }^{25}$ and Welsh participants, ${ }^{14}$ revealed a greater proportion of positive to negative comments (1:0.51 London; 1:0.61 Wales) than in SCPES (1:0.78). This effect may be because SCPES did not specifically ask patients to describe what they found good about their care. There were many similarities in the themes identified in all three surveys, including that patients commented on receiving poorer care at nights and at the weekend; and on issues with the role of primary care in cancer diagnosis. Many participants in SCPES noted poorer care when receiving care from staff who they perceived not to be cancer specialists. Analysis of English survey results indicated that patients in Trusts which had more cancer specialist nurses, reported a better experience of care coordination and emotional support. ${ }^{26}$ The issues around lack of involvement and choice in decision making, being given inconsistent or inappropriate information, and lack of signposting to support services, which were highlighted in SCPES, did not appear to emerge strongly in the free-text analysis of other surveys. It is not clear whether this is an effect of the difference in free-text questions and analysis between the surveys or if it reflects actual differences in the experience of patients with cancer between these countries. Nonetheless, communication emerged as a theme in all three surveys, both within health services and between health professionals and patients. Designing interventions to improve communication is a critical challenge in improving the delivery of cancer care. ${ }^{27} 28$

Two major aims of the current Scottish Government's cancer strategy are to improve cancer detection and aftercare. ${ }^{29}$ Our analysis suggests that many patients have significant problems with these two phases of care at present. There have been guidelines for the referral of suspected cancer cases in Scotland since $2002,{ }^{30}$ which have been revised in light of new research in 2007 and 2014; ${ }^{31}$ the National Institute for Health and Care Excellence also published suspected cancer referral guidelines in 2015. ${ }^{32}$ The Scottish Government launched the Detect Cancer Early Programme in 2012, developing projects with the NHS to increase 
screening uptake, increase diagnostic capacity, and work with GPs to promote referral or investigation for suspected cancer cases. ${ }^{33}$ Free-text comments in SCPES suggest that patients were less happy with the lead-up to diagnosis than at any other point in their treatment. Some made positive comments about the efficiency of national screening programmes, however, the majority of respondents were negative about the lead-up to diagnosis, particularly commenting on experiencing long waits and delays, having difficulty getting into the system, and poor communication. The timing of SCPES may be a factor in people having a less good experience of the lead-up to diagnosis, with participants for the survey having received a diagnosis between July 2013 and March 2014. It is possible the Detect Cancer Early Programme had not yet had an impact on processes around diagnosis for the cohort in this study. However, we found that patients with less common cancer types made a greater proportion of negative comments about the lead-up to diagnosis. The Detect Cancer Early Programme has focused on breast, colorectal and lung cancers, as they are the most common cancers in Scotland; ${ }^{34}$ our results suggest that patients with less common cancers are not benefiting from similar improvements to the early diagnosis system. Further, referral guidelines, and improvements in the capacity of screening and diagnostic services are aimed at tackling processes, rather than the patients' experiences of those processes. One of the main problems with the lead-up to diagnosis identified in this study was around poor communication at the time of diagnosis, with participants describing feeling that staff did not listen to them, or that they were not given information appropriate to their needs at that time. Many participants described feeling confused and anxious as a result of the way they were told about their diagnosis, and others experienced delays and confusion around diagnostic testing and once they got into the hospital system. Results from SCPES suggest that improving diagnostic pathways for less common cancers, and improving communication at the time of diagnosis would enhance the experience of this particularly worrying and stressful time. These results chime with those of another recently published analysis of free-text comments, which illustrates that patients may move backwards and forwards within the diagnostic pathway and that this is often complex and difficult to navigate. ${ }^{35}$

The relatively large proportion of negative comments indicate that not all patients with cancer in Scotland are receiving person-centred care. From the patients' perspective, all stages of the care continuum and every interaction with services have an impact on their experience. This survey identified problems with both interactions with health professionals and services and linkages between services. Participants described interacting with many different services, including GPs, charities, cancer services and other specialist servicescoordination of care between these services arose as an issue in multiple free-text comments, suggesting problems with fragmentation of care, lack of signposting, inconsistent information and the patient not knowing who to contact. Understanding and improving processes for administration, communication and coordination between services is vital to ensure a positive and high-quality experience for the patient. ${ }^{27}$ While improvement at an individual service level is important to enhance clinical effectiveness and safety, improvement efforts also need to take a 'whole systems' view in order to impact on the overall patient experience. A recent review of the relationship between integrated care and experience of patients with cancer found a positive association between greater integration of care and both patient experience, and professionals' behaviour and attitudes in cancer care, identifying the importance of (1) having a case manager or navigator, (2) the engagement of a multidisciplinary team in care and treatment, and (3) a continuous relationship between the case manager and healthcare professionals. ${ }^{36}$ The results of SCPES identified that participants were particularly positive about their experience when they felt they received treatment from a cohesive team, and negative about their experience when they felt they did not have a named contact who was available to help them with aspects of their care and provide information in a responsive and meaningful way.

SCPES provides detailed information about the experience of cancer care at a system level in Scotland. However, a survey of this nature is anonymous and there is a time lag between the experience of care and analysis, meaning the results have no direct impact for individual participants. Also, due to the distributed care of patients with cancer, it can be difficult to identify particular parts of the service which would benefit from organisational change. The measurement of patient experience should be timely and focused in order to provide information which is actionable in specific services. ${ }^{37}$ At an individual level, measurement of patient experience could provide valuable insight into issues with an individual's experience of care and provide real time feedback to help identify and resolve unmet needs. The SCPES results suggest that when patients have a negative experience of care their confidence in the system is shaken and they may feel more vulnerable when treatment comes to an end. Macmillan's Recovery Package advocates that all patients with cancer should receive a holistic needs assessment and care plan at key points of the cancer pathway, and a cancer care review completed by primary care within 6 months of the GP being informed of a patient's cancer diagnosis. ${ }^{38}$ If rolled out for all patients, these conversations could provide an opportunity to assess and monitor patients' experience of care and provide a mechanism to resolve issues for individual patients as they move through the care pathway. Sensitive, reliable and service-focused tools are needed to measure the experience of patients with cancer in real time to facilitate this process. ${ }^{37} 39$ 
The analysis of the free-text comments in SCPES has highlighted aspects of cancer care which are particularly important to patients. While many patients have a positive experience of cancer care, there are some key factors which contribute to negative experiences at all stages of the cancer pathway. The results of the survey provide important details of the experiences of care which may matter most to patients, suggesting areas for service improvement which will communicate to patients as individuals, and inspire greater confidence in the system of care. Our analysis also points to particular aspects of care which need attention, including the experience of the lead-up to diagnosis, the integration of care and monitoring patient experience in real time in order to ensure that we are truly responsive to the needs of people with cancer.

Acknowledgements The authors thank the patients who took the time to leave free-text comments in the survey. The authors also thank the Scottish Cancer Patient Experience Survey Steering Group for their work in guiding the design of the survey tool. The authors thank Andrew Paterson and Emma Milburn, Scottish Government and Kelly Shiell-Davis and Hanna Hine, Macmillan Cancer Support, for their help and support critically commenting on the survey report; and Patricia Aitchison, Research Fellow, NMAHP RU, University of Stirling, for her work in double coding.

Disclaimer The views are those of the authors and do not necessarily represent the views of Macmillan Cancer Support and the Scottish Government.

Competing interests None declared.

Ethics approval Public Benefits and Privacy Panel.

Provenance and peer review Not commissioned; externally peer reviewed.

Data sharing statement Both authors had substantial involvement in data analysis and writing up of this paper. The data for the study are the free-text responses to the 2015-16 Scottish Cancer Patient Experience Survey. The data were provided by the Scottish Government Analytical Services Division, following agreement from the . A full report is available from http://www.gov.scot/ Publications/2016/10/1882.

Open Access This is an Open Access article distributed in accordance with the Creative Commons Attribution Non Commercial (CC BY-NC 4.0) license, which permits others to distribute, remix, adapt, build upon this work non-commercially, and license their derivative works on different terms, provided the original work is properly cited and the use is non-commercial. See: http://creativecommons.org/ licenses/by-nc/4.0/

(c) Article author(s) (or their employer(s) unless otherwise stated in the text of the article) 2017. All rights reserved. No commercial use is permitted unless otherwise expressly granted.

\section{REFERENCES}

1. The Health Foundation. Person-centred care made simple. 2014 www.health.org.uk/sites/health/files/PersonCentredCareMadeSimple. pdf, (accessed 21 Dec 2016).

2. Department of Health. High Quality care for all: nhs Next Stage Review Final Report. London: The Stationery Office, 2008. www. gov.uk/government/uploads/system/uploads/attachment_data/file/ 228836/7432.pdf, (accessed 21 Dec 2016).

3. Doyle C, Lennox L, Bell D. A systematic review of evidence on the links between patient experience and clinical safety and effectiveness. BMJ Open 2013;3:e001570.

4. NHS England. Cancer news. www.england.nhs.uk/cancer/2016/10/ 04/cancer-ratings/, (accessed 21 Dec 2016).

5. Luxford K, Sutton S. How does patient experience fit into the overall healthcare picture? Patient Experience Journal 2014;1:20-7.

6. Ahmad AS, Ormiston-Smith N, Sasieni PD. Trends in the lifetime risk of developing Cancer in Great Britain: comparison of risk for those born from 1930 to 1960. Br J Cancer 2015;112:943-7.
7. Arora NK, Reeve BB, Hays RD, et al. Assessment of quality of cancer-related follow-up care from the Cancer survivor's perspective. J Clin Oncol 2011;29:1280-9.

8. Booij JC, Zegers M, Evers PM, et al. Improving cancer patient care: development of a generic cancer consumer quality index questionnaire for cancer patients. BMC Cancer 2013;13:203.

9. Damman OC, Hendriks M, Sixma HJ. Towards more patient centred healthcare: a new consumer quality index instrument to assess patients' experiences with breast care. Eur J Cancer 2009;45:1569-77.

10. Malin JL, Ko C, Ayanian JZ, et al. Understanding cancer patients experience and outcomes: development and pilot study of the Cancer Care Outcomes Research and Surveillance patient survey. Support Care Cancer 2006:14:837-48.

11. Department of Health. National Cancer patient experience survey Programme - 2010 National Survey Report. Quality Health 2010; www.quality-health.co.uk/resources/surveys/national-cancerexperience-survey/2010-national-cancer-patient-experience-survey, (accessed 21 Dec 2016).

12. Iversen $\mathrm{HH}$, Holmboe $\mathrm{O}$, Bjertnæs $\mathrm{OA}$. The Cancer patient experiences questionnaire (CPEQ): reliability and construct validity following a national survey to assess hospital Cancer care from the patient perspective. BMJ Open 2012;2:e001437.

13. Quality Health. Cancer patient experience survey 2015 all northern Ireland Report. www.quality-health.co.uk/resources/surveys/ northern-ireland-cancer-patient-experience-survey/2015-northernireland-cancer-patient-experience-survey/northern-ireland-cancerpatient-experience-survey-reports, (accessed 21 Dec 2016).

14. Bracher M, Corner DJ, Wagland R. Exploring experiences of Cancer care in Wales: a thematic analysis of free-text responses to the 2013 Wales Cancer Patient Experience Survey (WCPES). BMJ Open 2016;6:e011830.

15. Scottish Government. Scottish Cancer patient experience survey 2015/16. http://www.gov.scot/Publications/2016/06/3957/ downloads, (accessed 21 Dec 2016).

16. Asprey A, Campbell JL, Newbould J, et al. Challenges to the credibility of patient feedback in primary healthcare settings: a qualitative study. Br J Gen Pract 2013;63:200-8.

17. Riiskjær E, Ammentorp J, Kofoed PE. The value of open-ended questions in surveys on patient experience: number of comments and perceived usefulness from a hospital perspective. Int J Qual Health Care 2012;24:509-16.

18. Quality Health. National Cancer patient experience survey. http:// www.ncpes.co.uk/index.php/reports/guidance/2486-2015-nationalcancer-patient-experience-survey-questionnaire/file, (accessed 21 Dec 2016).

19. Braun V, Clarke V. Using thematic analysis in psychology. Qual Res Psychol 2006;3:77-101.

20. Namey E, Guest G, Thairu L, et al. Data reduction techniques for large qualitative data sets. In: Guest G, MacQueen KM, eds. Handbook for Team-Based Qualitative Research. Plymouth, UK AltaMira Press, 2007:137-61.

21. Scottish Government. Introducing the Scottish Index of multiple deprivation 2016. www.gov.scot/Resource/0050/00504809.pdf, (accessed 21 Dec 2016).

22. Bone A, McGrath-Lone L, Day S, et al. Inequalities in the care experiences of patients with cancer: analysis of data from the National Cancer patient experience survey 2011-2012. BMJ Open 2014;4:e004567.

23. Williams B. Patient satisfaction: a valid concept? Soc Sci Med 1994;38:509-16.

24. Jahagirdar D, Kroll T, Ritchie K, et al. Using patient reported outcome measures in health services: a qualitative study on including people with low literacy skills and learning disabilities. BMC Health Serv Res 2012;12:431.

25. Wiseman T, Lucas G, Sangha A, et al. Insights into the experiences of patients with Cancer in London: framework analysis of free-text data from the National Cancer patient experience survey 2012/2013 from the two London Integrated Cancer systems. BMJ Open 2015:5:e007792.

26. Griffiths P, Simon M, Richardson A, et al. Is a larger specialist nurse workforce in Cancer care associated with better patient experience? Cross-sectional study. J Health Serv Res Policy 2013;18:39-46.

27. Dossett LA, Hudson JN, Morris AM, et al. The primary care provider (PCP)-cancer specialist relationship: a systematic review and mixedmethods meta-synthesis. CA Cancer J Clin 2017;67.

28. Easley J, Miedema B, Carroll JC, et al. Coordination of Cancer care between family physicians and Cancer specialists: importance of communication. Can Fam Physician 2016;62:e608-15. 
29. Scottish Government. Beating Cancer: ambition and Action. 2016, http://www.gov.scot/Publications/2016/03/9784/downloads (accessed 21 Dec 2016).

30. Scottish Executive. Scottish referral guidelines for suspected Cancer. 2007, http://www.sehd.scot.nhs.uk/mels/HDL2007_09.pdf, (accessed 21 Dec 2016).

31. Healthcare Improvement Scotland. Scottish referral guidelines for suspected Cancer. 2014, http://www. healthcareimprovementscotland.org/our_work/cancer_care_ improvement/programme_resources/scottish_referral_guidelines. aspx, (accessed 21 Dec 2016).

32. Hamilton W, Hajioff S, Graham J, et al. Suspected Cancer (part 2--adults): reference tables from updated NICE guidance. BMJ 2015;350:h3044.

33. Scottish Government. Detect Cancer Early. www.gov.scot/Topics/ Health/Services/Cancer/Detect-Cancer-Early (accessed 21 Dec 2016).
34. NHS Scotland Quality Improvement Hub. Detect cancer early. www. qihub.scot.nhs.uk/quality-and-efficiency/cancer/detect-cancer-early. aspx, (accessed 21 Dec 2016).

35. Parsonage RK, Hiscock J, Law RJ, et al. Patient perspectives on delays in diagnosis and treatment of Cancer: a qualitative analysis of free-text data. Br J Gen Pract 2017;67.

36. Foglino S, Bravi F, Carretta E, et al. The relationship between integrated care and Cancer patient experience: a scoping review of the evidence. Health Policy 2016;120:55-63.

37. Manary MP, Boulding W, Staelin R, et al. The patient experience and health outcomes. N Engl J Med 2013;368:201-3.

38. Macmillan Cancer Support. The Recovery Package: sharing good practice. 2015, www.macmillan.org.uk/_images/recovery-packagesharing-good-practice_tcm9-299778.pdf, (accessed 21 Dec 2016).

39. Saunders C, Carter DJ, Jordan A, et al. Cancer patient experience measures: an evidence review. J Psychosoc Oncol 2016;34:200-22. 